\title{
Necrotizing Fasciitis of the Breast Underlying an Autoimmune Disease
}

\author{
Jaouad Yousfi, Soukaina Oumlil, Laila Benjilali, Lamiaa Essaadouni \\ Department of Internal Medicine, University Hospital of Mohammed VI, Marrakesh, Morocco
}

Doi: 10.12890/2021_002434 - European Journal of Case Reports in Internal Medicine - ○ EFIM 2021

Received: 01/03/2021

Accepted: $11 / 03 / 2021$

Published: $15 / 04 / 2021$

How to cite this article: Yousfi J, Oumlil S, Benjilali L, Essaadouni L. Necrotizing fasciitis of the breast underlying an autoimmune disease. EJCRIM 2021;8: doi:10.12890/2021_002434.

Conflicts of Interests: The Authors declare that there are no competing interests.

This article is licensed under a Commons Attribution Non-Commercial 4.0 License

\section{ABSTRACT}

Necrotizing fasciitis is a serious soft tissue infection that causes necrosis of the subcutaneous tissues and the muscle fascia. It is associated with a high mortality rate of around $25 \%$. Necrotizing fasciitis of the breast is a rare entity. It is a rapidly progressive life-threatening condition which can lead to sepsis with multiple organ failure. We describe a case of necrotizing fasciitis of the right breast in a 48-year-old patient diagnosed with systemic sclerosis-rheumatoid arthritis overlap syndrome.

\section{LEARNING POINTS}

- Necrotizing fasciitis of the breast is a very challenging diagnosis due to its rarity and similarity with simple breast infection.

- It is a life-threatening condition which can lead to systemic shock and multiple organ dysfunction syndrome and death.

- It may occur in patients with rheumatic diseases treated with corticosteroids and immunosuppressant drugs.

\section{KEYWORDS}

Necrotizing fasciitis, autoimmune disease, methotrexate

\section{INTRODUCTION}

Patients with rheumatoid arthritis and systemic sclerosis have higher mortality than the general population. This is due in part to the increasing incidence of infections ${ }^{[1]}$. We report a case of necrotizing fasciitis (NF) of the right breast in a patient with systemic sclerosisrheumatoid arthritis overlap syndrome, which had been treated with steroids and methotrexate for 25 years. This is the first reported case of NF of the breast in a patient with a history of autoimmune disease.

\section{CASE DESCRIPTION}

A 48-year-old woman had been diagnosed at the age of 23 with systemic sclerosis and erosive rheumatoid arthritis, which was treated with steroids (prednisone $10 \mathrm{mg}$ daily) and methotrexate (15 mg weekly).

The patient presented with a 2-day history of mastodynia, a rash on the right breast (Fig. 1) and a fever of $38.5^{\circ} \mathrm{C}$. Right breast examination revealed a painful purplish rash and blisters. Left breast examination was normal. The patient also had ipsilateral lenticular axillary lymphadenopathy (Fig. 1).

The patient's laboratory results revealed leukocytes of $16,170 / \mathrm{mm}^{3}$ with an absolute neutrophil count of $14,430 / \mathrm{mm}^{3}$. C-reactive protein was $24 \mathrm{mg} / \mathrm{l}$ and the erythrocyte sedimentation rate was $20 \mathrm{~mm} / \mathrm{hr}$. Tests for syphilis, HIV, hepatitis B and hepatitis C were all negative. Microbiological analysis of pus, obtained by ulcer swab, revealed enterococcus and third-generation cephalosporin-resistant Escherichia coli. The breast ultrasound showed right mastitis. 
The patient was treated with the antibiotics imipenem and amikacin, and was taken to the operating theatre for surgical necrosectomy with skin grafting. Histopathological examination of the tissues showed acute inflammatory suppurative lesions with no signs of malignancy (Figs. 2 and 3).
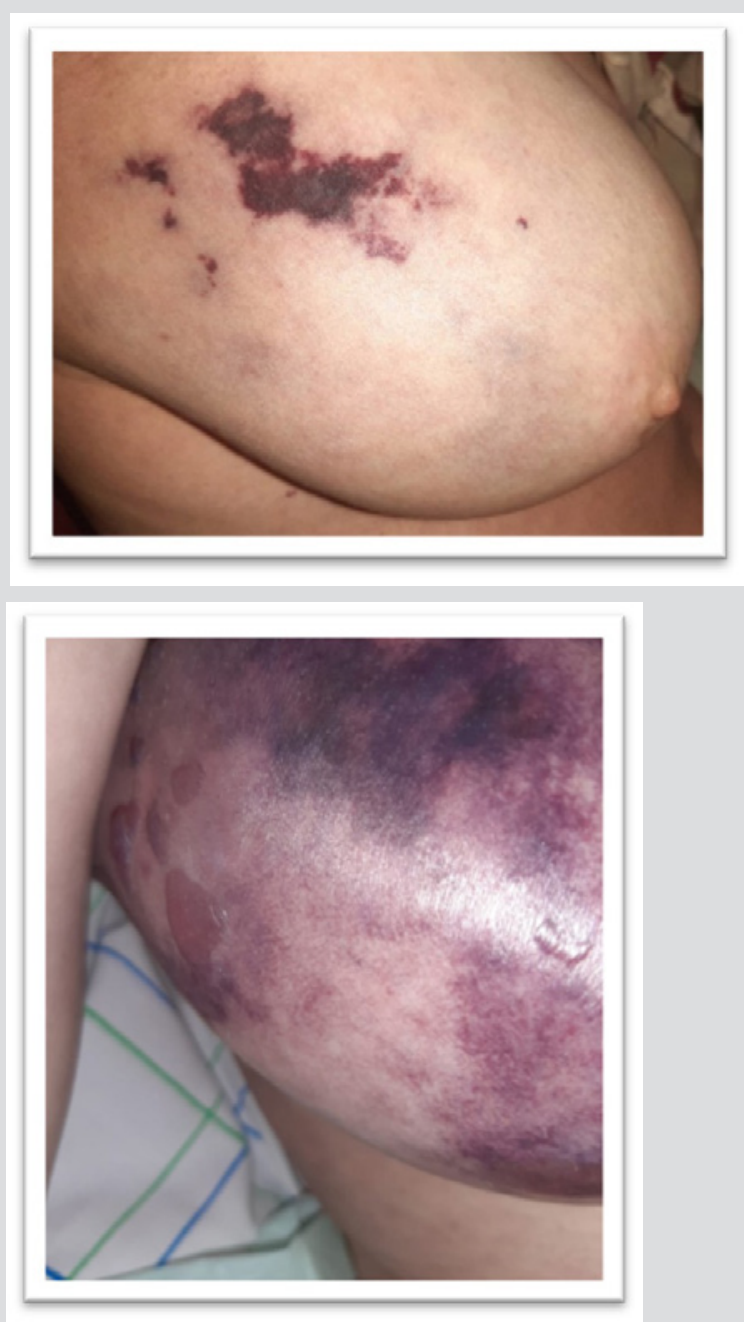

Figure 2. The patient's right breast after 1 week
Figure 1. The patient's right breast initially

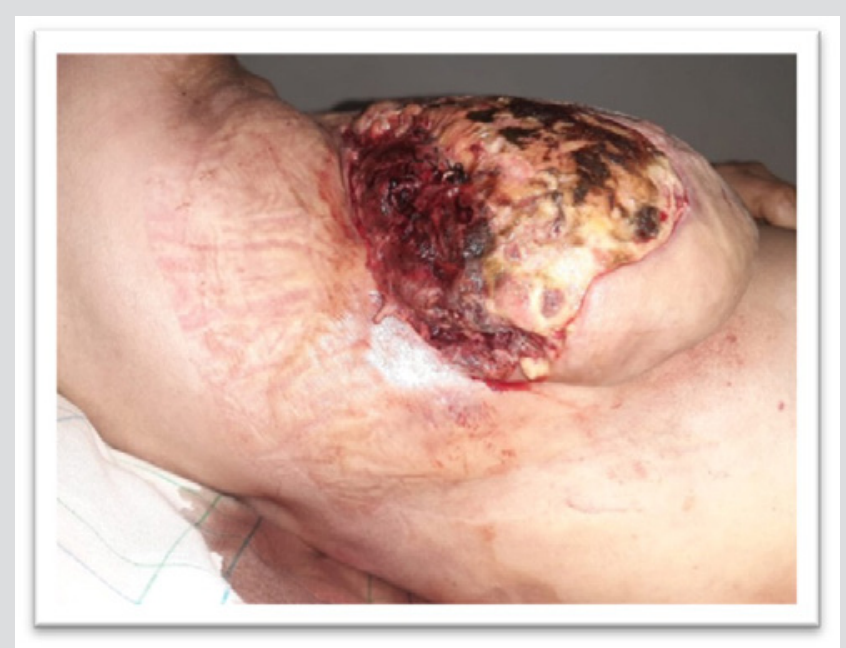

Figure 3. The patient's right breast after necrosectomy

The diagnosis of NF of the breast with an underlying autoimmune disease was established. The methotrexate was discontinued, and steroid tapering was initiated. At 4-month follow-up, the patient was apyretic and the biomarkers of inflammation were back to normal.

\section{DISCUSSION}

NF is a rare life-threatening infection of the soft tissues characterized by subtle, rapid onset of spreading inflammation and necrosis starting from the fascia, muscles and subcutaneous fat, with subsequent necrosis of the overlying skin. Patients with diabetes and immunosuppression have an increased risk of developing NF ${ }^{[2]}$.

The clinical features of NF are erythema, swelling and pain at the affected site. Severe pain disproportionate to local findings, combined with systemic toxicity should raise the suspicion of NF. However, these symptoms are non-specific. NF can initially be misdiagnosed and it can be difficult to differentiate it from cellulitis. As the infection progresses, the skin becomes increasingly tense and erythematous with indistinct margins. It may change colour sequentially from a red-purple to a dusky blue before progressing to necrosis and the formation of haemorrhagic bullae ${ }^{[3]}$. 
Cases of NF of the breast are rare. It usually occurs unilaterally, although bilateral NF of the breast has been reported. Predisposing factors for the development of NF of the breast include preceding mastitis or a breast abscess, a history of trauma, minor cuts and burns, drug use, insect bites, puerperium and lactation. This condition is also frequently encountered in patients with diabetes mellitus, peripheral vascular disease or immunosuppression ${ }^{[4]}$.

Several cases of NF have been reported in patients with rheumatic diseases including systemic sclerosis, rheumatoid arthritis, systemic lupus erythematosus and ankylosing spondylitis. Treatment with steroids and other immunosuppressive agents may have further affected the increased susceptibility to infection in these patients. Steroids decrease the inflammatory response, effector cell response in cell-mediated immunity, and immunoglobulin synthesis. Disease severity and steroid use are associated with an increased risk of infection, while low-dose methotrexate does not appear to increase infection risk significantly ${ }^{[5]}$.

In our case, we believe that the immunocompromised status of the patient was the main factor behind the development of NF of the breast. Prolonged steroid and methotrexate administration might have increased the risk of infection and caused fragility of skin tissue, which in turn allowed easy access of bacteria. To our knowledge, there are no cases in the literature of NF of the breast underlying an autoimmune disease.

\section{CONCLUSION}

Necrotizing fasciitis of the breast is a very challenging diagnosis due to its rarity and similarity with a simple breast infection. Clinicians must hold a high index of suspicion if pain is disproportionate to the signs or a painful swollen breast co-presents with sepsis. Furthermore, we believe that this case is a reminder of the possibility of severe infections in patients receiving corticosteroid therapy or disease-modifying agents for autoimmune diseases.

\section{REFERENCES}

1. Doran MF, Crowson CS, Pond GR, O'Fallon WM, Gabriel SE. Frequency of infection in patients with rheumatoid arthritis compared with controls: a population-based study. Arthritis Rheum 2002;46(9):2287-2293.

2. Singh G, Sinha SK, Adhikary S, Babu KS, Ray P, Khanna SK. Necrotising infections of soft tissues-a clinical profile. Eur J Surg 2002;168(6):366-371.

Hasham S, Matteucci P, Stanley PRW, Hart NB. Necrotising fasciitis. BMJ 2005;330(7495):830-833.

Marks B, Fasih T, Amonkar S, Pervaz M. Necrotising fasciitis of the breast: a rare but deadly disease. Int J Surg Case Rep 2019;65:10-14.

Mok MY, Wong SY, Chan TM, Tang WM, Wong WS, Lau CS. Necrotizing fasciitis in rheumatic diseases. Lupus 2006;15(6):380-383. 